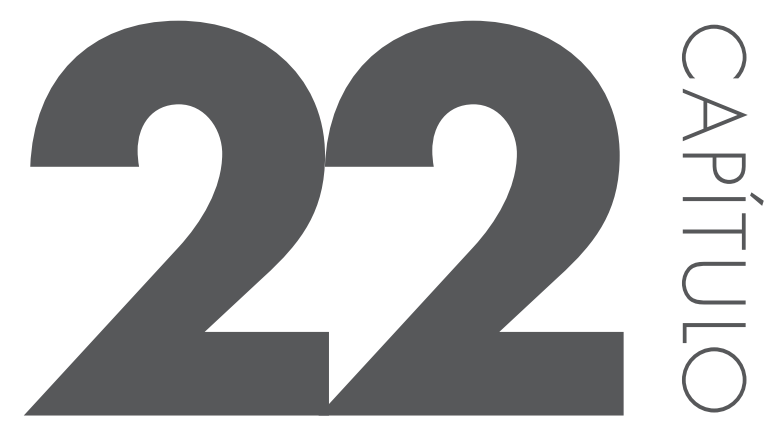

\title{
UMA BREVE ANÁLISE DE MANUSCRITOS OITOCENTISTAS DE CATALÃO SOB A PERSPECTIVA DOS GÊNEROS DISCURSIVOS
}

Almeida, Mayara Aparecida Ribeiro de ${ }^{\text {*}}$; Oliveira-Silva, Maiune de 2; Paula, Maria Helena de ${ }^{3}$

1 Universidade Federal de Goiás - Regional Catalão (UAELL)

2 Universidade Federal de Goiás - Regional Catalão (UAELL)

3 Universidade Federal de Goiás - Regional Catalão (UAELL)

* email: may_aparecida20@hotmail.com

\section{RESUMO}

No estudo em tela, realizamos uma breve análise de manuscritos (notariais e eclesiásticos) oitocentistas de Catalão, na perspectiva dos gêneros discursivos de Bakhtin (1997), com vistas a traçar um painel desses gêneros, dando destaque, ainda, para sua historicidade que, conforme se observa, remonta ao período escravocrata, haja vista que todos eles fazem menção aos negros escravos. Para tanto, classificamo-los, baseando-nos em Bellotto (2002) e identificamos quatro tipologias documentais, a saber: seis escrituras públicas de compra e venda de escravos, uma escritura pública de hipoteca de escravos, um traslado de carta de liberdade e dois livros de 
registro paroquial de batizado. A posteriori, assinalamos suas três partes constituintes, tais que: conteúdo, construção composicional e estilo, em que identificamos a necessidade de recorrer a leis e constituições da época, dentre as quais destacamos as "Constituiçõos Primeiras do Arcebispado da Bahia" e a "Lei do Ventre Livre" que nos possibilitaram não apenas a compreensão acerca de suas tessituras textuais, bem como estabelecer relação entre a temática dos manuscritos e a história e cultura da então Cidade de Catalão.

Palavras-chave: Filologia; Gênero discursivo; Escravidão. MANUSCRITOS OITOCENTISTAS DE CATALÃO SOB A PERSPECTIVA DOS GÊNEROS DISCURSIVOS", p. 381-404 . In: Seminário de Pesquisa, Pós- Graduação e Inovação da Regional Catalão (2. : 2014 : Goiás) Coletânea Interdisciplinar em Pesquisa, Pós-Graduação e Inovação - Volume 2 : Humanidades e Letras. Anais [livro eletrônico] / organizado por Adriana Freitas Neves, Idelvone Mendes Ferreira, Maria Helena de Paula, Petrus Henrique Ribeiro dos Anjos. São Paulo: Blucher, 2015. ISBN: 978-85-8039-111-4, DOI 10.5151/9788580391114-V2_Cap22 


\section{PALAVRAS INICIAIS}

O presente trabalho intenciona dar continuidade às discussões empreendidas nas pesquisas de iniciação científica desenvolvidas por nós durante nossa trajetória na graduação em Letras - Português e Inglês. Ao longo desse período, realizamos três pesquisas no âmbito do Programa Institucional de Bolsa de Iniciação Científica (PIBIC), todas elas financiadas pelo Conselho Nacional de Desenvolvimento Científico e Tecnológico (CNPq) e vinculadas ao projeto "Em busca da memória perdida: estudos sobre a escravidão em Goiás”, o qual recebe fomento da Fundação de Amparo à Pesquisa do Estado de Goiás (FAPEG) e é coordenado pela professora Doutora Maria Helena de Paula.

Por meio da execução dessas pesquisas, tivemos a oportunidade de conhecer e estudar muitos documentos manuscritos exarados em Catalão, de natureza notarial e eclesiástica, que trazem em seus fólios menção aos negros escravos, dando-nos, assim, condição de rememorar um pouco da história escravocrata ocorrida no sudeste goiano. Além disso, pudemos conhecer e ampliar o nosso conhecimento acerca da filologia, uma ciência secular que enxerga no texto seu objeto de estudo, suporte através do qual dados linguísticos, históricos, culturais, ideológicos, entre outros, podem ser recuperados.

Dentre todo o saber que obtivemos acerca desta ciência, um deles assenta-se na observação de todas as particularidades do texto que se está analisando, estando o gênero discursivo entre esses aspectos estudados. Assim, o conhecimento do gênero discursivo sobre o qual o documento foi elaborado torna-se importante uma vez que essas informações nos possibilitam observar, com mais propriedade, o tema, o conteúdo e a construção composicional do texto. Desta feita, além de permitir que o pesquisador identifique as três partes constituintes do gênero discursivo, disponibiliza a oportunidade de conhecer a história desse gênero, contribuindo, portanto, com a execução da função transcendente do estudo filológico, responsável por descobrir a história subjacente na escrita de cada documento, tal como nos ensina Spina (1977).

No encalço deste entendimento, buscamos, dentro da perspectiva dos gêneros do discurso de Bakhtin (1997), descrever cada um dos documentos que utilizamos como corpus ao longo de nossa trajetória acadêmica, oferecendo informações relativas às suas partes constituintes, a saber: aos seus conteúdos ou seleções de temas; aos estilos ou escolhas dos recursos linguísticos e às construções composicionais ou suas formas de organização. 
Nosso olhar será lançado sobre códices notariais e eclesiásticos, de modo particular sobre seis escrituras públicas de compra e venda de escravos, uma escritura pública de hipoteca de escravos, um traslado de carta de liberdade e dois livros de registro paroquial de batizado.

Para trabalhar com os manuscritos notariais, selecionamos do vasto acervo digital do projeto referido retro oito (8) documentos constantes em dois livros do Cartório de $2^{\circ}$ Oficio de Notas de Catalão. Do primeiro códice, o Livro de Notas do $2^{\circ}$ Tabelliaõ - Carlos Antonio de Andrade, o qual traz termo de abertura datado de 1886, examinamos três documentos (fólios 1r a 2r; 8v a 10r; $23 \mathrm{v}$ a 25 r). Do segundo livro, estudamos cinco manuscritos (fólios 53r a 54r; 54r a $54 \mathrm{v} ; 55 \mathrm{r}$ a $55 \mathrm{v}$; $56 \mathrm{v}$ a $57 \mathrm{v} ; 57 \mathrm{v}$ a $58 \mathrm{v}$ ), todos exarados em 1861 . Para abordar os documentos eclesiásticos, nos assentamos no estudo de dois Livros de Registro de Batizados da Paróquia Mãe de Deus, expedidos em Catalão, o primeiro datado dos anos de 1837-1838 e o segundo, entre os anos de 1871 a 1885.

Esperamos, deste modo, traçar um panorama de cada um destes gêneros discursivos aqui contemplados e estabelecer relação entre a temática dos manuscritos com a história e cultura de Catalão e região, realçando, assim, o trato aos negros escravos, uma vez que estes são mencionados em todos os gêneros aqui contemplados. Ademais, ensejamos contribuir com outras pesquisas que se dediquem ao estudo de documentos manuscritos notariais e eclesiásticos, facilitando o acesso às informações contidas em tais textos.

\section{ARCABOUÇO TEÓRICO}

Para que uma pesquisa possa ser bem realizada, alcançando os objetivos propostos, é necessário em meio a outros saberes, a utilização de um conhecimento específico que lhe dê subsídios, conhecimento esse chamado de teoria. A teoria é uma forma de olhar para o objeto de pesquisa, respondendo, inclusive, pela metodologia a ser seguida, conforme será detalhado na seção seguinte.

Ante este pensamento, devemos informar que o olhar que lançamos sobre o corpus em questão assenta-se nos estudos filológicos, tendo como principal referência Spina (1977, p.75), para quem “[...] a filologia não subsiste se não existe o texto (pois é o texto a sua razão de ser), partamos dele para, de uma forma abrangente, configurar o seu campo".

Depreendemos dessa assertiva que o objeto de estudo da filologia é o texto e, sobretudo, é ele que dita o campo de trabalho a ser trilhado pelo pesquisador, o que aponta para o caráter interdisciplinar dessa ciência que 
deve vincular-se à outras áreas do conhecimento, a fim de compreender o texto. Deste modo, é possível identificar em trabalhos dessa ordem a recorrência a disciplinas auxiliares, como a História, a Geografia, a Linguística, a Arqueologia, a Paleografia, a Codicologia, o Direito, entre tantas outras. Insta mencionar que foi o próprio texto que indicou por qual/quais destas deveríamos buscar informações que contribuíssem para o seu entendimento.

Ademais, Spina (1977) lista ainda as três funções da atividade filológica, a saber: função substantiva, função adjetiva e função transcendente. A primeira função refere-se a etapa em que o filólogo se concentra no texto para explicá-lo, restituí-lo à sua forma genuína e prepará-lo para ser publicado. Dentre esses itens, o autor esclarece que a etapa mais importante está no processo em que o texto é preparado para ser publicado, ou seja, em sua edição. A edição é uma forma de reproduzir o texto, podendo esta se dar de muitas formas, a depender dos objetivos imbuídos nessa atividade e no público alvo almejado.

Nesta pesquisa, fizemos uso de edições semidiplomáticas, elaboradas em conformidade com as Normas para transcrição de documentos manuscritos para a História do Português do Brasil, presentes em Megale e Toledo Neto (2005). Tais edições foram realizadas por nós em nossas pesquisas de iniciação científica ao longo de nossa trajetória acadêmica. Assim, acreditamos que a utilização destas contribuiu muito em nossa tarefa de estudar os gêneros textuais, pois se caracterizam em uma lição conservadora, muito fiel ao documento original e que foi elaborada com vistas a facilitar o acesso por parte de seus consulentes, tal como pode ser observado nos dizeres de Megale e Toledo Neto (2005, p.13)

[...] a lição semidiplomática desenvolve as abreviaturas, marcando em itálico as letras omitidas, à luz de ocorrência plena no próprio documento ou em documentos da época; intervém nos eventuais erros, marcando a intervenção conforme consta das normas de transcrição, ou abrindo nota de rodapé, quando necessário, o que torna o manuscrito mais facilmente legível, preservado o estado de língua em que foram escritos os documentos.

Retomando as explicações acerca das funções da atividade filológica, consideremos a segunda, a função adjetiva, que se encarrega por responder indagações que não estão presentes no texto, mas que são deduzidas sobre ele, por exemplo: a sua autoria, a sua datação, a biografia do autor, a sua valorização perante os demais textos de mesma natureza. 
Por fim, a terceira função, a transcendente, é responsável por descobrir a história contemplada na tessitura textual. Mediante as informações presentes nas linhas e entrelinhas do texto, o filólogo busca reconstituir a vida de um povo em determinado recorte temporal, rememorando-lhe dados históricos, culturais, religiosos e ideológicos.

No presente estudo, prezamos alcançar apenas a terceira função dentre as mencionadas. E para chegarmos a esse entendimento acreditamos que o conhecimento dos gêneros textuais dos documentos se fez muito relevante. Para o tratamento dessa questão, nos baseamos nos estudos de Bakhtin (1997), em sua obra "Estética da criação verbal", mais precisamente no capítulo intitulado "Os gêneros do discurso" em que toda a teoria acerca dos gêneros textuais está elencada.

Bakhtin (1997) parte da língua para falar dos gêneros do discurso. Segundo seu pensamento, todas as atividades humanas estão relacionadas a ela, que pode ser utilizada de formas muito variadas, acompanhando, assim, a própria dinâmica das esferas da atividade humana e a intencionalidade em cada uma delas. A utilização da língua é concretizada mediante os enunciados (orais e escritos), proferidos em determinadas circunstâncias da atividade humana. Nos dizeres de Bakhtin (1997, p. 280), os enunciados vistos dentro de uma esfera específica da atividade humana são "tipos relativamente estáveis de enunciados”, nomeados por ele de gêneros do discurso.

Por meio desses enunciados é possível observar as finalidades de cada esfera linguística e as suas condições de produção, o que se torna factível mediante o estudo de seu conteúdo temático, pelo seu estilo de linguagem (recursos lexicais, fraseológicos e gramaticais da língua) e acima de tudo por sua construção composicional. Esses três elementos encontram-se presentes nos enunciados e são determinados pelo campo da comunicação em que são empregados.

O conteúdo temático do gênero refere-se aos assuntos que podem, devem ou que se espera que sejam contemplados em um determinado gênero textual. $O$ estilo verbal responde pelos recursos linguísticos selecionados - recursos lexicais, fraseológicos e gramaticais. A construção composicional consiste na forma de organização do enunciado.

O autor esclarece ainda que, em razão das imensuráveis possibilidades da atividade humana, torna-se possível afirmar que existe uma diversidade muito grande de gêneros do discurso. E esse número torna-se mais expressivo ainda, uma vez que, dentro de cada campo da interação humana, inúmeros gêneros são utilizados.

Bakhtin (1997) ainda ressalta a importância de atentarmos para a diferença entre os gêneros discursivos primários (simples) e secundários 
(complexos). Os gêneros primários são aqueles que surgem nos atos de comunicação imediata. Por sua vez, os gêneros secundários surgem de um convívio cultural mais complexo, resultado das diversas interações baseadas na escrita. Esses gêneros têm por característica a incorporação e a reelaboração dos gêneros primários.

Insta agora trazermos à baila um questionamento primordial, responsável por justificar a utilização desse conhecimento acerca dos gêneros discursivos em nosso trabalho de conclusão de curso. Consoante o que nos diz Bakhtin (1997, p. 283), a observação deste conteúdo tem uma importância capital, tal como pode ser observado no seguinte trecho:

Uma concepção clara da natureza do enunciado em geral e dos vários tipos de enunciados em particular (primários e secundários), ou seja, dos diversos gêneros do discurso, é indispensável para qualquer estudo, seja qual for a sua orientação específica. Ignorar a natureza do enunciado e as particularidades de gênero que assinalam a variedade do discurso em qualquer área do estudo linguístico leva ao formalismo e à abstração, desvirtua a historicidade do estudo, enfraquece o vínculo existente entre a língua e a vida. A língua penetra na vida através dos enunciados concretos que a realizam, e é também através dos enunciados concretos que a vida penetra na língua. O enunciado situa-se no cruzamento excepcionalmente importante de uma problemática.

Assim, acreditamos que, para chegarmos a um real entendimento sobre a história contida no documento, devemos passar antes pelo estudo do gênero discursivo que dá suporte a essas informações.

\section{PERCURSO METODOLÓGICO}

Assim como a utilização de uma teoria que sustente nossas pesquisas, faz-se de igual importância uma metodologia que nos permita alcançar os objetivos esperados. Deste modo, primeiramente nos detivemos na leitura de obras teóricas que nos deram o embasamento necessário para a realização deste estudo, tais como Spina (1977), Bakhtin (1997) e Bellotto (2002).

Dando continuidade à pesquisa, passamos para a etapa em que nos encarregamos de classificar os gêneros e descrevê-los, ofertando àqueles que se interessem o maior número possível de informações acerca destes documentos 
notariais e eclesiásticos, que foram exarados nos oitocentos. Para esta etapa, baseamos em Bellotto (2002), haja vista que Bakhtin (1997) não classifica os gêneros discursivos e dedica-se apenas à sua discussão teórica.

Cumpre especificar, ademais, que não identificamos nesta autora a classificação e a descrição de um gênero em específico, o escrito particular, o nos que levou a recorrer a Cardoso (2009) em seu trabalho monográfico, em que esse tipo relativamente estável de enunciado é abordado.

Em seguida, nos detivemos no estudo dos documentos manuscritos que nos servem de corpus, identificando, a priori, cada um de seus elementos constituintes. No que se refere à identificação de cada um dos elementos constituintes desses gêneros, que levasse em consideração o contexto histórico em que os documentos foram escritos, fez-se necessário ainda a observância ao direito cartorial e canônico.

Em leitura acurada destes documentos, observamos menção a algumas Leis do período Imperial (Lei N ${ }^{\circ} 2.040$ de 28 de setembro de 1871, a Lei do Ventre Livre, e a Lei de 28 de setembro de 1885, a Lei dos Sexagenários). Sendo assim, os informes dessas leis foram abarcados neste estudo, porquanto em cumprimento ao que o próprio Spina (1977) nos fala, é o documento que vai orientar sobre quais ciências o pesquisador deve recorrer para a execução de sua tarefa.

Com relação aos documentos eclesiásticos, uma obra que se fez imprescindível para a compreensão e delimitação das características dos registros de batizados foram as "Constituições do Arcebispado da Bahia”, elaboradas pelo D. Sebastião Monteiro da Vide ([1719/1720] 1853) e amplamente utilizadas em todo o território brasileiro no período colonial, a qual dispunha como os registros de batizados deveriam ser redigidos, apresentando, inclusive, um modelo de assento.

Por fim, tendo já identificado cada uma dessas partes, nos é possível então observar, em linhas gerais, sobre a finalidade em se escrever tais documentos e, sobretudo, tecer considerações sobre a história que os motivou e lhes deu origem. Tal momento do estudo demandou de nossa parte o conhecimento prévio de dados históricos de Catalão; para tanto, nos baseamos nos estudos de Palacín e Moraes (1994), com destaque ainda para a história da escravidão ocorrida neste cenário, como evidenciado nos documentos. 


\section{OS GÊNEROS DISCURSIVOS DOS MANUSCRITOS}

No tocante aos gêneros abarcados neste estudo, acreditamos lidar com três gêneros discursivos, a saber: escritura pública, traslado e registro paroquial, tomando por base o que consta em Bellotto (2002). A considerar as especificidades, há escritura pública de compra e venda de escravo, escritura pública de hipoteca de escravo, traslado de carta de liberdade e registro de batismo.

Com relação ao tipo de gênero, todos esses são secundários, uma vez que surgiram a partir de situações complexas (ideológicas) que se encontram assentadas na escrita. A fim de conceder mais clareza à classificação dos gêneros aqui abarcados, observemos o quadro ilustrativo logo abaixo:

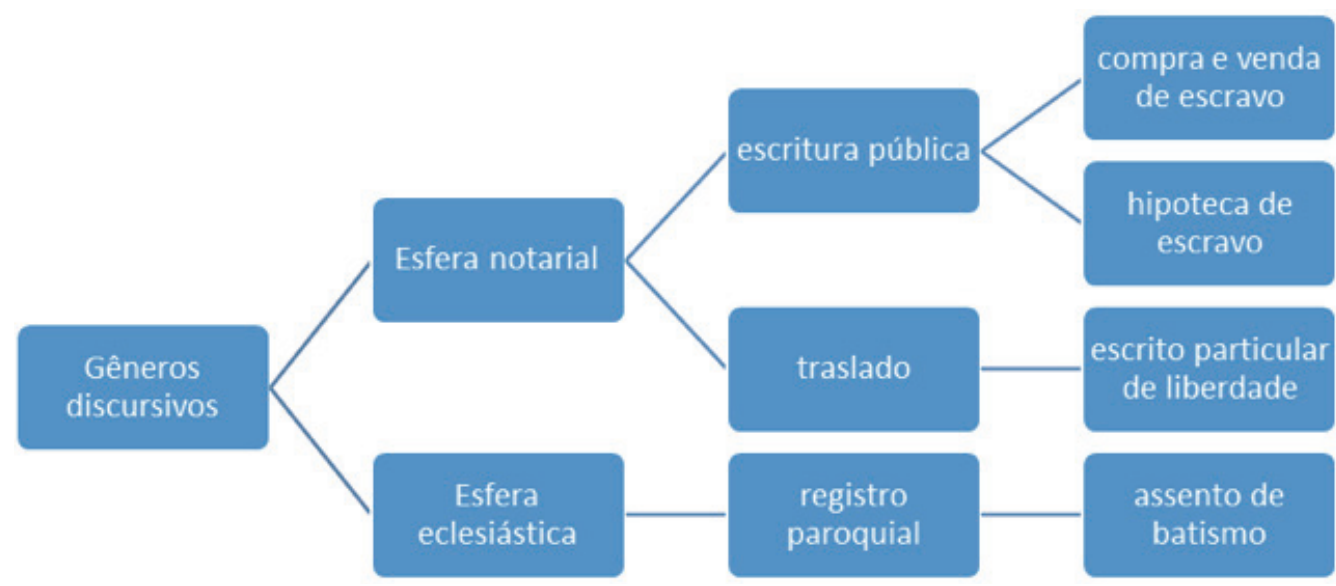

Quadro 1- classificação dos gêneros discursivos em manuscritos catalanos oitocentistas.

Sabemos da dificuldade enfrentada pelos pesquisadores em entenderem documentos dessa natureza, exarados em tempos longínquos como estes em estudo, porquanto apresentam um vocabulário arcaico e/ou ainda por essas palavras referirem-se a assuntos de uma área específica. Nesse sentido, propositamos analisar esses gêneros do discurso tomando como ponto de partida o contexto em que eles foram produzidos e também a historicidade do próprio gênero, haja vista que, tal como nos informa Bakhtin (1997), os gêneros são criados/modificados em razão das vicissitudes dos senhores humanos.

O conhecimento particularizado desses gêneros e de suas partes constituintes auxilia o filólogo em sua tarefa de editar os documentos manuscritos, permitindo a ele não apenas identificar corretamente as palavras, bem como realizar essa etapa de forma mais ligeira. Ademais, tomar ciência deste assunto torna mais 
fácil, em muitas circunstâncias, o cumprimento da função transcendente do labor filológico, responsável por compreender a história por trás da escrita dos documentos.

\subsection{A ESFERA NOTARIAL: A ESCRITURA PÚBLICA}

Segundo Bellotto (2002, p. 67), a escritura é “um documento diplomático, testemunhal de assentamento, notarial. Registro autêntico de um contrato ou de uma transação feito por um oficial notarial". Inicialmente, vale assinalar que, segundo Nunes Contreras (1981, apud BELLOTTO, 2002, p. 36), por documento diplomático entende-se aqueles que são testemunhos escritos de ordem jurídica, redigidos em concordância a fórmulas préestabelecidas a fim de dar-lhes fé e força comprobatória.

Consoante Bellotto (2002), os documentos notariais devem ser incluídos no acervo dos documentos diplomáticos porquanto estes também apresentam força legitimadora e são submetidos à sistematização imposta pelo Direito com o fito de adquirirem efeito de validade. Ademais, observamos que além de ser redigido por um notário (tabelião ou escrivão), ter fórmulas pré-estabelecidas, a escritura requer, ainda, a presença de testemunhas.

Retomando Bakhtin (1997), observamos que existe uma riqueza e diversidade de gêneros do discurso que resultam igualmente das infinitas possibilidades da atividade humana e que em cada grupo dessas atividades, do mesmo modo, identifica-se um repertório amplo de gêneros que, com o passar do tempo, vão se ampliando e diferenciando à medida que esse campo torna-se mais complexo, ou seja, à proporção que vão surgindo novas situações na vida dessas pessoas que requerem, para tanto, modificações e/ou criações de novos gêneros.

Assim sendo, do mesmo modo, o gênero escritura pública divide-se em vários tipos. Em nosso corpus, identificamos escrituras públicas de compra e venda de escravos e escritura pública de hipoteca de escravos, exaradas nos anos de 1861, 1887 e 1888. Essas escrituras apresentam basicamente a mesma estrutura (construção composicional) e o mesmo estilo, divergindo apenas a finalidade imbuída nesta transação.

Referentemente ao aspecto estilístico das escrituras públicas, nota-se que todas foram elaboradas em uma linguagem formal; são textos expositivos e descritivos e apresentam frases padronizadas, como: "epor ter feito l esta venda de sua livre e espontanea I vontade" e " cedia na pessôa do dito com- I prador toda posse, jûs edominio que I no dito escravo elle vendedor tinha $\mid$ podendo possuil-o por seu como fica I sendo d'ora em diante, e por esta seobri- I gava á 
fazer apresente venda firme e I valiosa em qualquer tempo" (escritura pública de compra e venda do escravo Joaõ, fólio 1 verso).

Além disso, constata-se, ainda, que muitos verbos encontram-se na voz passiva. Segundo Bechara (2009, p. 222), a voz passiva é uma "forma verbal que indica que a pessoa é o objeto da ação verbal. A pessoa neste caso, dizse paciente da ação verbal [...]. A passiva é formada com um dos verbos ser, estar, ficar, seguido do particípio". No corpus, a voz passiva se faz presente nos trâmites de transcrição das informações dadas pelas partes envolvidas na transação, uma vez que o cartório onde se lavra a escritura não necessariamente é o local onde as partes acordam sobre a venda e compra ou hipoteca - é, sobretudo, o local e o agente legitimador da ação, já ocorrida. Para o registro destas informações, são usados verbos que referem a ações passadas entre as partes, na voz passiva, não na voz ativa em tempo passado.

Vejamos um exemplo retirado de uma das escrituras públicas de compra e venda, com estrutura passiva formulaica, repetida nas escrituras objeto de nosso estudo: "pelo referido vendedor me foi declarado I que possuindo livremente um escravo I por nome Joaõ, prêto, (o qual sua mu- \|1v\| mulher Dona Maria Roza da Silva obteve por I herança de seu primeiro marido Clau- I dino Francisco Pereira.)". (fólio 1 recto e 1 verso, grifo nosso).

Destacamos, ainda, nos documentos em estudo, que os tabeliões colocavam as frases tomando como principal a presença da informação, sem se preocuparem com os elementos coesivos comuns à língua. Sem o costume com a leitura deste gênero, o leitor pode não entender o documento com esta estrutura, o que corrobora a importância de que busque compreender esses gêneros, a fim de que tal empecilho não comprometa o seu entendimento do texto.

No que se refere à construção composicional destas escrituras, sejam elas de compra e venda e/ou hipoteca de escravos, observa-se que elas possuem basicamente o mesmo formato.

Partindo desse mesmo pressuposto, de que esses documentos estão estruturados sem muita variação, Spina (1977, p. 53) afirma que estes são constituídos de duas partes, uma interna e outra externa, tal como pode ser verificado a seguir:

Intrinsecamente o documento é constituído de duas partes: uma interior, que constitui o corpo do documento e contém o fato registrado: é o TEXTO; outra exterior, que serve de moldura do documento, e contém as fórmulas que conferem a ele perfeição legal e personalidade, servindo também para a sua autenticação, datação e publicidade: é o PROTOCOLO. 
A parte externa do documento (protocolo) é composta de duas partes, a saber: a abertura e o encerramento. A abertura consiste no título do documento, utilizado com vistas a facilitar sua localização nas suas futuras consultas, como se vê: "Escriptura publica de compra evenda de I escravo que como vendedor faz oSenhor I Alferes Prudencio da Silva Leaõ ecomo I comprador oSenhor Jose Pereira Claudio I na forma abaixo:" (escritura pública de compra e venda do escravo Joaõ, fólio 1 recto).

Por sua vez, o encerramento é composto por uma expressão de encerramento, seguida das assinaturas (sinal público e raso) do tabelião responsável pela redação da escritura, das assinaturas das partes envolvidas, bem como das testemunhas que, conforme informamos na seção anterior, faziam-se extremamente necessárias, tal como se observa no seguinte excerto:

Ede como assim odisseraõ e contracta-l raõ, do que dou fe, me pediraõ esta l escriptura que sendo-hes lida e achan- I do conforme a acceitaraõ eassignaraõ I com as testemunhas - DoSenhor David Ca- I moẽs de Mendonça e Jose Vieira da I Silva. Eu Joaõ Gonsalves Lima Se- I gundo Tabelliaõ Vitalicio oescrevi e I assigno em publico eraso de que uso I[espaço] Em testemunho [Joaõ Gonsalves Lima] [sinal público] De verdade I Prudencio da Silva Leaõ I José Pereira Claudio (escritura pública de compra e venda do escravo Joaõ, fólio 2 recto).

Insta esclarecer neste ponto em que consistem os sinais público e raso. Esses dois sinais faziam-se necessários para darem fé pública aos documentos escritos pelos notários. O primeiro consiste em uma assinatura diferenciada, manuscrita e de difícil reprodução, que deveria ser criado pelos tabeliães logo após assumirem seus cargos, a fim de que este pudesse ser reconhecido por outras autoridades. Por sua vez, o sinal raso consistia na assinatura por extenso do tabelião.

Por seu turno, a parte interna é o texto propriamente dito. Segundo Spina (1977), esta se inicia com a notificação com relação à natureza do documento, seguida da descrição do objeto que se está negociando, das partes envolvidas, dos impostos recolhidos pela transação, entre outros. Em nosso estudo, todos os documentos reportam à transação cujo bem negociado era o negro escravo.

É na parte interna desses documentos, então, que identificamos as particularidades de cada documento. As escrituras de compra de venda de escravos, conforme nos foi possível constatar, eram documentos que tinham como fito tornarem válidas as transações de compra e venda dos cativos 
(escravos), em que era transferida a posse, jus e domínio do bem escravo. Com relação ao conteúdo esperado neste tipo de documento, observamos que estes deveriam conter sumariamente o nome dos escravos, do comprador, do vendedor, das testemunhas, entre outros. Além disso, devia-se informar o valor pago na transação, os impostos recolhidos, bem como a menção a algumas cláusulas especiais quando havia a necessidade.

Tendo uma finalidade distinta, as escrituras de hipoteca de escravos serviam para assegurar que dívidas contraídas entre duas partes seriam quitadas. Para tanto, o devedor hipotecava seu escravo e o colocava a serviço de seu credor até que a dívida fosse completamente paga. São constantes nesse tipo de registro cláusulas como: valor do empréstimo, o não pagamento de jornal pelo serviço cumprido pelo cativo, a delimitação do tempo em que esta dívida deveria ser sanada e as orientações sobre que medidas seriam tomadas no caso do não pagamento da dívida ou da morte do devedor.

Com relação a estas disposições, na hipoteca a que nos referimos, observamos que durante esse período o cativo deveria ficar sobre o domínio do credor sem receber jornal (remuneração em dinheiro feita por dia de trabalho) por isso. Ademais, verificou-se que caso o devedor morresse antes de reembolsar o credor, o escravo passaria legalmente a pertencer a este último.

Tendo em vista que os gêneros sofrem alterações ao longo do tempo, reflexo das mudanças ocorridas na sociedade, buscamos comparar o que se distingue nos documentos notariais exarados em 1861 para aqueles escritos em 1886 e 1887. É com relação às descrições dos escravos que elas podem ser visualizadas, quando observamos que as escrituras realizadas em $1886 \mathrm{e}$ 1887 trazem um acervo descritivo muito mais amplo que as escrituras públicas exaradas em 1861.

Enquanto esta última nos informa apenas o nome dos escravos, suas etnias ou características físicas e suas idades ("um escravo crioulo de nome Vicente I deidade de cinco enta etres annos mais I oumenos", fólio 55 recto), a primeira, por sua vez, oferta um leque muito amplo de informações, como podemos observar nesse trecho:

Neste acto I me foi apresentado pelo vendedor á I matricula do theôr seguinte: Relaçaõ I número 26 dos escravos pertencente ao Alferes Pru- I dencio da Silva Leaõ, residente no Muni- I cipio de Catalaõ - Artigo $2^{\circ} \mathbb{S} \mathbb{S} 1^{\circ}$ do regulamento. I Número de ordem na presente matricula 50 - Número de I ordem na matricula anterior 375 - Número de ordem I na relaçaõ 1Nomes - Joaõ, côr preta, idade 45 annos dez mezes ecinco 
dias, estado, casado, I natural de Goyaz, Profissaõ lavrador, filho I de Joaõ, valor dado conforme a tabella I seis centos mil reis (escritura pública de compra e venda do escravo João, 1886, fólio 1 verso).

Para a compreensão dessas diferenças observamos o contexto histórico em que estes documentos foram produzidos e constatamos que eles sofreram interferências, em especial, de duas leis. A primeira delas e a que mais interferiu na escrita desses documentos foi a Lei $\mathrm{n}^{\circ} 2040$ de 28 de setembro de 1871, chamada de Lei dos Nascituros ou Lei Rio Branco, popularmente conhecida como a Lei do Ventre Livre, uma vez que declarava livres todos os filhos de escravas nascidos após a sua promulgação.

Assim, ordenou-se em seu artigo $8^{\circ}$ que todos os escravos do Império fossem matriculados: "O Govèrno mandará proceder à matrícula especial de todos os escravos existentes do Império, com declaração de nome, sexo, estado, aptidão para o trabalho e filiação de cada um, se fôr conhecida". Posteriormente, em $1^{\circ}$ de dezembro de 1871 , foi publicado o Decreto $\mathrm{n}^{\circ} 4835$, em que se ordenava que após o dia 30 de setembro de 1872 não poderia ser lavrado nenhum tipo de documento mencionando o negro escravo, sem conter tais descrições.

Outra lei que interferiu na escrita destes documentos foi a Lei $\mathrm{n}^{\circ} 3.270$ de 28 de setembro de 1885, chamada de Lei dos Sexagenários, que regulamentava a extinção do elemento servil, concedendo a liberdade aos escravos com mais de 60 anos de idade. Tal lei, além desta disposição primordial, trazia no teor de seu texto uma tabela com os valores dos escravos; esta tabela era baseada no sexo e na idade do cativo, em que quanto mais novo o escravo mais elevado era o seu preço. Assim, ordenou-se que fosse realizada uma nova matrícula dos cativos, acrescentando a essas descrições listadas anteriormente o valor dos escravos de acordo com a tabela de preços.

\subsection{A ESFERA NOTARIAL: O TRASLADO}

O traslado é outro gênero notarial que, segundo Bellotto (2002, p. 89), consiste em um "documento diplomático testemunhal comprobatório, notarial. Cópia ou reprodução integral de documentos autênticos originais, assentados em livros próprios, na área notarial”. Era comum nos oitocentos que os documentos fossem escritos nas fazendas e que, posteriormente, fossem levados até os cartórios, a fim de ganharem legitimidade. Na região de Catalão, isso também se fazia comum, uma vez que, conforme consta em Palacín e Moraes (1994), a maioria da população morava na zona rural. 
Assim, o traslado a que nos reportamos neste trabalho refere-se a uma escritura de liberdade, elaborada com vistas a conceder a manumissão (alforria) ao escravo o que, conforme pudemos verificar, não significava, de fato, sua liberdade. Diferentemente das escrituras que tratamos anteriormente, esta se configura como um escrito particular.

Para a compreensão acerca deste gênero discursivo, fazemos uso do que nos fala Cardoso (2009, p. 167-168), para quem o escrito particular consiste em uma:

Composição documental por escrito que registra um ato individual de vontade de uma pessoa com valor legal específico entre as partes, o qual poderia ser substituído por escritura pública; comum em épocas em que o acesso a estabelecimentos cartoriais para registro de compra e venda era restrito ou inexistente.

Tendo explanado em que consiste um traslado e o que é um escrito particular convém, neste momento, dizer especificamente sobre o conteúdo, a construção composicional e o estilo de um traslado de escritura de liberdade.

Conforme observamos na análise desse documento, sua estrutura pode ser dividida também de acordo com o esquema proposto por Spina (1977), a saber: em parte externa e parte interna. Como parte externa do traslado, integram o termo de abertura e o termo de encerramento.

No primeiro, observa-se que além de ser informado o título do documento, o tabelião faz saber que os donos do escravo alforriado pagaram o imposto de selo, que se fazia necessário para a redação desse documento, como se ilustra neste excerto: "Traslado deuma Escriptura de liber dade Ipassada por Vicente Pereira da Lus esua mulherl Anna deJesus afavor de seu escravo pardo de I $<$ Sello $>$ nome Misael = Pagou número 130 deSello dusentos réis | Catalaõ 5 de Junho de 1861. O I Agente Satyro Domingues I Escrivam interino" (fólio 53 recto).

O segundo, por sua vez, é composto por uma expressão de encerramento, seguida das assinaturas do tabelião e de quem compareceu em sua presença levando a escritura para ser legitimada. Observemos:

Segundo o que se I contava declarava adicta Carta de liberda I de que bem efiel mente copiei da I propria aque mereporto empoder I dequem a trouxe que foi Joaquim o Al- II54r\| Alves deSantana aquem entrego $\mid$ para alevar aseu destino, eporverdade I elle aqui assignase commigo Camillo <Pago $2 \$ 000$ | Novaes> I Jose de Oliveira 
Novaes Tabelliaõ que I escrevi conferi eassigno.|[espaço]|Camillo José de Oliveira Novaes [sinal público] IJoaquim Alves deSantana (traslado de uma escritura de liberdade, fólio 53 verso e 54 recto).

De outro modo, a parte interna refere-se à transcrição integral do escrito particular. $\mathrm{O}$ escrito particular de carta de liberdade, por sua vez, é composto das seguintes informações: data e local em que a carta foi escrita; nome dos donos dos escravos; nome do escravo alforriado, de que forma essa liberdade foi concedida (gratuitas ou onerosas, ressaltando que por onerosas enquadramse aquelas que requeriam o pagamento em dinheiro e/ou com serviços prestados pelo escravo); quem escreveu a carta (muitas vezes as cartas eram escritas por outras pessoas que não eram os donos dos cativos porquanto esses não sabiam ler e escrever); o local e a data em que foi escrito; e, por fim, as assinaturas dos donos do escravo e das testemunhas.

A respeito do estilo apresentado nessa escritura de hipoteca, constatase que assim como o que se observou na seção anterior, apresenta um texto expositivo e descritivo. No entanto, este se difere porquanto na parte interna do texto, onde se transcreve o escrito particular, observamos uma liberdade maior na escrita do documento, posto que não foi escrita por um notário; ainda assim, uma frase formulaica, comum a outros gêneros cartoriais, pode ser encontrada, como: "sendo este beneficio feito muito de I nossas livres iespontanias vontades, esem I constrangimento depessoa alguma" (fólio 53 recto).

\subsection{A ESFERA ECLESIÁSTICA: OS ASSENTOS DE BATISMO}

O registro paroquial, segundo Bellotto (2012, p. 85), é um “documento diplomático testemunhal de assentamento. Documento componente dos acervos dos arquivos paroquiais da Igreja Católica e que são, via de regra: livros de batizado, de casamento, de óbito, de crisma, de tombo, de contabilidade etc."

Em nosso estudo, conforme disposto anteriormente, trabalhamos com dois livros de batizados da Paróquia Nossa Senhora Mãe de Deus, o primeiro exarado nos anos de 1837 e 1838 e o segundo, entre os anos de 1871 a 1885 .

De acordo com as "Constituições Primeiras do Arcebispado da Bahia", elaboradas por

D. Sebastião Monteiro da Vide ([1719/1720] 1853), para quem o batismo para ser sacramentado necessita de matéria, forma e ministro. A matéria consiste na água com a qual é feita a ablução (purificação por meio da água) do corpo; a forma, por sua vez, consiste nas palavras, instituídas por Jesus Cristo e que devem ser proferidas pelo sacerdote no ato do batismo, podendo 
ser pronunciada em latim (Ego te baptizo in nomine Patris, et Filii, et Spiritus Sancti) ou ainda em português (Eu te baptizo em nome do Padre, e do Filho, e do Espirito Santo). Requer-se, ademais, a presença de um ministro para realizar o sacramento, representado pelo Pároco da Freguesia.

Segundo esta obra, o assento no livro de batismo serve para atestar o parentesco espiritual adquirido entre os padrinhos, o batizando e seus pais. Assim, dispõe-se ainda como o registro deve ser redigido, em cujo final fazia-se necessária a assinatura do pároco ou sacerdote que realizou o sacramento.

e os assentos dos baptisados se escreverão na fórma seguinte: Aos tantos de tal mez, e de tal anno baptizei, ou baptizou de minha licença o Padre N. nesta, ou em tal Igreja, a N. filho de N. e de sua mulher N. e lhe puz os Santos Oleos: forão padrinhos N. e N. casados, viúvos, ou solteiros, freguezes de tal Igreja, e moradores em tal parte (CONSTITUIÇÕES PRIMEIRAS DO ARCEBISPADO DA BAHIA, Título XX, p. 29).

Desta feita, com relação ao conteúdo desses assentos, tomando por base o que consta nas constituições e aquilo que é comum aos dois livros de registro, nota-se que eles contêm basicamente: a data em que o batismo foi realizado; a informação de quem realizou este sacramento (se o pároco ou algum sacerdote mediante licença); nome da criança e de seus pais (no caso de esses serem escravos, informavam-se suas características físicas ou étnicas e o nome de seus senhores); a forma e o local em que o batismo foi realizado; o nome dos padrinhos (casos estes fossem escravos também informava-se o nome de seus donos); data em que o assento foi realizado e a assinatura do pároco responsável pela freguesia.

Vale ressaltar que identificamos algumas diferenças na redação dos dois livros de registro de batismo, posto que os documentos exarados em 1837 e 1838 apresentam uma descrição muito mais rica com relação às pessoas envolvidas neste ato litúrgico, como: a identificação de quem compareceu na presença do padre levando consigo a criança a ser batizada (no caso dos escravos quem cumpria essa função era, na maioria dos casos, os seus senhores); também se informa o horário em que a criança nasceu; com relação aos senhores de escravos, eram dispostos dados como o local em que moravam e sua profissão ou ocupação na época.

No tangente ao estilo, ou seja, aos recursos linguísticos selecionados para a tessitura dos gêneros (recursos lexicais, fraseológicos e gramaticais), observamos primeiramente que estes se caracterizam por terem uma linguagem formal e 
rebuscada, em que são descritos fatos ocorridos e que requerem a escrita desses documentos (neste caso do registro paroquial), a fim de provarem a realização efetiva de tal ato.

Além disso, verifica-se que, assim como os documentos da esfera cartorial, estes também apresentam um texto formulaico, diferindo-se de um texto para outro apenas as informações pessoais dos leigos envolvidos no ato do batismo: o batizando, seus pais, seus padrinhos e os senhores de escravos. Essa afirmação pode ser confirmada quando mostramos anteriormente de que forma os assentos deveriam ser lançados no livro de registro, de acordo com as ordenações da Igreja.

Embora os assentos de batismo não pertençam à esfera notarial, acreditamos ser possível aplicar neste caso também a estrutura proposta por Spina (1977), em que os documentos são compostos por uma parte interna e outra externa. Como parte externa dos assentos de batismo, integra o termo de encerramento, composto por uma expressão de encerramento e a assinatura do pároco da freguesia, conforme pode ser observado neste excerto: “[...] epara constar fis este Termo em que me assigno I OVigario EncomendadolFrancisco Xavier Matozo [Francisco Xavier Matozo]" (fólio 1 recto)

A parte interna, propriamente dita, é aquela em que são dispostas a primeira parte do assento em que é informada a data de lançamento do registro de batismo no livro paroquial e quem realizou o sacramento, seguida das informações relativas às pessoas envolvidas no batismo: nome da criança batizada, nome de seus pais, nome dos padrinhos, nomes dos senhores de escravos etc., tal como ilustrado no seguinte trecho:

[...] Aos trinta de Maio de mil oito centos etrinta esete nesta |Freguezia da Senhora Madre de Deos da Villa do Catalaõ, em a IFazenda denominada macacos, onde eu abaixo assignado me I achava, compareceo ahi Manoel da Silva, e Santos, com seolescravo nascido a onze do corrente, pelas onze horas da noite, e lfilho legetimo de seos escravos, Joaquim criolo, e Maria Cabrale no mesmo dia Supra, baptizei Solemnemente, epus osSantoslolios, eforaõ Padrinhos Joze Luis da Silva, e Antonia da ISilva Roza. (fólio 1r)

Diante desse exemplo, observa-se que apesar de seguir uma estrutura rígida, os assentos de batismo nos possibilitam conhecer muito das pessoas envolvidas na realização do sacramento do batismo. 


\section{REMEMORANDO O PASSADO HISTÓRICO DE CATALÃO}

Em nossa pesquisa, tomamos como material documentos da esfera cartorial e eclesiástica, os quais, além de nos auxiliarem na compreensão dos gêneros discursivos, colocaram-nos a necessidade de nos enveredarmos pelo contexto histórico em que foram escritos, para compreendermos o passado escravocrata o qual remontam.

Com relação aos primeiros, nota-se que foram criados para atender à necessidade de comprovar legalmente as negociações envolvendo cativos, bem como a libertação de escravos, tratados explicitamente como "bens materiais" dos seus senhores, condição atribuída a homens e mulheres vítimas do sistema de servidão que vigorava no Brasil Colonial.

Assim sendo, esses cativos eram vistos por seus “donos” apenas como uma força de trabalho, que deveriam gastar suas vidas para àqueles servirem. De acordo com Palacín e Moraes (1989) e conforme pudemos corroborar ao longo de nossa trajetória acadêmica, os escravos no sudeste de Goiás foram destinados ao trabalho doméstico e às zonas rurais, em que suas principais atividades eram o serviço agrícola e agropecuário.

Também no traslado de escritura de liberdade essa ideologia fica nítida, uma vez que a liberdade que se ofereceu ao escravo foi uma liberdade onerosa, tal como classifica Mattoso (2003), haja vista que requeria do cativo a prestação de serviços durante um período que se estipulava no próprio documento, invalidando, assim, o sentido de liberdade atribuído a esse documento.

No tocante aos documentos eclesiásticos, verificam-se duas finalidades distintas. De um lado, a intenção da Igreja, para a qual estes registros foram elaborados a fim de atestarem a inserção das crianças, fossem elas brancas ou negras, livres ou escravas, na fé católica, conforme disposto no livro "Constituições Primeiras do Arcebispado da Bahia". Evidenciam, ainda, que o batismo dos cativos se fazia obrigatório tanto da perspectiva dos senhores de escravos como dos membros da Igreja, constituindo-se uma forma de reafirmar a supremacia da cultura brasileira sobre a cultura de homens e mulheres vindos da África, configurando-se uma forma de opressão no que de mais simbólico pode ter uma pessoa, as suas práticas religiosas, linguísticas e suas relações de convivência familiar.

Por outro lado, conforme observamos nos estudos que se dedicam ao estudo dos documentos eclesiásticos voltados a essa temática, estes serviram para outras motivações específicas. Segundo Silva (2008), para os proprietários de escravos fazia-se importante levar os filhos de suas escravas para receberem 
o sacramento do batismo e juntamente a isso assentar esse batismo sob forma de registro nos livros paroquiais porquanto em tais registros era informado a quem o escravo (na maioria dos casos crianças) pertencia, o que colocava à disposição destes senhores um documento diplomático, legitimado pela Igreja, que lhe garantia a posse do recém-batizado.

Cabe considerarmos, ainda, o que o ato de receber o batismo representava para aqueles que eram vítimas de um sistema de servidão. Para estes, o mais importante não era o batismo em si, mas a escolha de um padrinho que, segundo a própria doutrina da Igreja Católica, passava a ter um laço espiritual com o batizando e com seus pais. Assim, escolher um padrinho era uma estratégia de sobrevivência para estes, que viam nesse ato uma maneira de lograrem melhores condições de vida ou, ainda, receberem suas alforrias, o verdadeiro anseio de todos aqueles presos a este sistema.

$\mathrm{Na}$ escolha dos padrinhos, via-se uma oportunidade de estabelecer laços com aqueles que pertenciam à mesma classe social (a de servidão), o que ofertava a estes a certeza de que teriam pessoas com quem poderiam contar nas adversidades da vida. Em contrapartida, escolher um padrinho branco e, de preferência de poder aquisitivo alto, poderia garantir ao cativo uma ascensão social, uma vez que sendo afilhado ou compadre de um homem branco, teria a possibilidade de transitar entre os brancos e dispor de regalias que não eram concedidas a todos os escravos.

Como vimos, o estudo desses documentos manuscritos mostraramnos que os gêneros do discurso surgem e vão sofrendo alterações em razão das próprias mudanças e necessidades do ser humano, que fazem uso desses gêneros do discurso para suas diversas atividades; no nosso estudo, serviram para legitimar a visão que se tinha dos cativos, no Brasil, a saber: de homens e mulheres vistos como bens materiais, cuja submissão à supremacia dos homens brancos era legitimada pelas ações oficiais da Lei e da Igreja, como configuram os documentos com fé pública (as escrituras lavradas por notários em cartórios), ou sob a égide da Igreja (os registros de batizado).

\section{CONSIDERAC̣ÕES FINAIS}

No presente estudo, tivemos como propósito estudar gêneros que pertencem à esfera eclesiástica e cartorial, haja vista que estes serviram de suporte para o registro de fatos históricos que muito nos interessam. Neles, são relatados acontecimentos dos oitocentos em Catalão, envolvendo negros escravos, nos possibilitando compreender um pouco sobre a história destes homens e 
mulheres, vítimas do sistema de servidão que prevaleceu não apenas no território brasileiro, tendo perdurado em outros países até recentemente, como reflexo de uma política europeia de soberania sobre povos e territórios.

No entanto, para acessarmos tais informações, fez-se de fundamental importância o estudo da história desses documentos, que realizamos na perspectiva de Bakhtin (1997). Mais que identificar suas partes constituintes, pudemos conhecer a história do desenvolvimento desses gêneros do discurso, mostrando que os gêneros são perpassados pela realidade das pessoas que deles se valem na interação social diária.

Esperamos, de tal modo, contribuir com pesquisadores que se dediquem ao labor filológico, especialmente aqueles que tenham como corpus de suas pesquisas documentos destas naturezas. Ademais, ensejamos ter suscitado questões e até mesmo concorrido com os trabalhos que se dedicam a rememorar a escravidão. De modo particular, cremos ter colaborado com o desenvolvimento do projeto "Em busca da memória perdida: estudos sobre a escravidão em Goiás", conforme disposto no livro "Constituições Primeiras do Arcebispado da Bahia” o qual é coordenado pela Prof ${ }^{a} \operatorname{Dr}^{a}$ Maria Helena de Paula e ao qual este estudo se vincula. 


\section{Title: A Brief Analysis Of Manuscripts Nineteenth-Century Catalan Under The Perspective Of Gender Discursive}

\section{Abstract}

In the present paper, we perform a brief analysis of nineteenth-century manuscripts (notarial and ecclesiastical) of Catalan, in the perspective of discursive genres of Bakhtin (1997), in order to perform a panel of these genres, giving prominence also for its historicity that, as observed, dates back to the slavery period, considering that they all make mention of the black slaves. To this end, we classify them, based in Bellotto (2002) and identified four typologies documentary, namely: six public deed of purchase and sale of slaves, a deed of mortgage slaves, a copy letter of freedom and two parish book of record of baptism. Subsequently, we pointed its three constituent parts, such that: content, style and compositional construction, wherein we identified wherein we identify the need to observe the laws and constitutions of the era, among which we highlight the "Constitutions of the First Archbishopric of Bahia" and the "Law of the Free Womb" which enabled to us not only to understanding its textual constructions as well as establish the relationship between the theme of the manuscripts and the history and culture of the then City of Catalan.

Keywords: Philology; Discourse genre; Slavery. 


\section{REFERÊNCIAS}

ANDRADE, Carlos Andrade de. Livro de Notas do $2^{\circ}$. Tabelliaõ (1886). Cartório do $2^{\circ}$. Ofício - Tabelionato de Catalão: Catalão-G0, 2007.

BAKHTIN, Mikhail. Os gêneros do discurso. In: . Estética da criação verbal. São Paulo: Martins Fontes, 1997, p. 278-327.

BECHARA, Evanildo. Moderna gramática portuguesa. 37. ed. Rio de Janeiro: Nova Fronteira, 2009. BELLOTTO, Helósa Liberalli. Como fazer análise diplomática e análise tipológica de documento de arquivo. São Paulo: Arquivo do Estado/Imprensa Oficial do Estado de São Paulo, 2002. (Projeto Como Fazer; vol. 8).

CÂMARA DOS DEPUTADOS. Lei $\mathbf{n}^{0}$ 3.270, de 28 de Setembro de 1885. Disponível em: <http://www2. camara.gov.br/legin/fed/lei/1824-1899/lei-3270-28-setembro-1885-543466publicacaooriginal-53780-pl.html >. Acesso em: 20 maio 2012.

CARDOSO, Claudinei Vaz. Estudo filológico e lingǘstico sobre a escravidão na cidade do Catalaõ. 2009, 182f. Monografia (Especialização em Letras), Universidade Federal de Goiás, Campus Catalão, Curso de Letras. Catalão-G0, 2009.

COSTA, Cônego Luis Antonio da. Registros de Batizados da Paróquia Nossa Senhora Mãe de Deus. Parochia Nossa Senhora Mãe de Deus. 100 fólios (52 fólios ms). 1871-1885.

MATOZO, Francisco Xavier Matozo (OVigario Encomendado). Livro de Registros de Batizados da Paróquia Nossa Senhora Mãe de Deus. Parochia Nossa Senhora Mãe de Deus. 52 fólios manuscritos. 1837-1838. MATTOSO, Kátia de Queirós. Ser escravo no Brasil. São Paulo: Brasiliense, 1982.

MEGALE, Heitor; TOLEDO NETO, Silvio de Almeida. Por minha letra e sinal: documentos do ouro do século XVIII (Coleção Diachronica). Cotia-SP: Ateliê, 2005.

PALACíN, Luís; MORAES, Maria Augusta Sant'Anna. História de Goiós (1722-1972). 6. ed. Goiânia: Ed. UCG, 1994.

PRESIDÊNCIA DA REPÚBLICA. Decreto $\mathbf{N}^{\circ} \mathbf{4 . 8 3 5}$, de $\mathbf{1}^{\circ}$ de Dezembro de 1871. Disponivel em <www. planalto.gov.br/ccivil_03/decreto/Historicos/DIM/DIM4835.htm>. Acesso em: 20 maio 2012.

SILVA, Sidney Pereira da. Os registros de batismo e as novas possibilidades historiográficas. Disponivel em: <hittp://www.historiahistoria.com.br/materia.fm?tb=artigos\&id=53. Acesso em: 10 out. 2014. SPINA, Segismundo. Introdução à Edótica. São Paulo: Cultrix/EDUSP, 1977.

VIDE, Sebastião Monteiro da. Constituições Primeiras do Arcebispado da Bahia. 3. ed. São Paulo: Tipografia. 1853. 